\title{
Nutrition education appropriate for the long-term management of diabetes in the community
}

\section{By D. R. R. Williams, University Department of Community Medicine, Addenbrooke's Hospital, Hills Road, Cambridge CB2 $2 Q Q$}

The term 'community' has several meanings which depend on the context in which it is used. In the present paper the word is used in the same way as in the term 'community nurse', i.e. denoting care taking place outside the hospital.

The long-term management of diabetes, and this of course includes nutrition education, is predominantly a community rather than a hospital problem. For a number of reasons, it is likely that this will become more so rather than less so in the foreseeable future.

Doney, a general practitioner in Winchester, reported that only $27 \%$ of the 122 diabetics in his practice were attending hospital regularly for diabetic review (Doney, 1976). In London, Yudkin (Yudkin et al. 1980) found this percentage to be 46 , while in a recent study in Cambridgeshire (Williams, 1982 ) the figure of $29 \%$ (similar to that in Winchester) was found. In this latter study, hospital attendance showed the expected relationship to age and current treatment (see Table r) in that insulin-treated patients were more likely to be attending hospital than non-insulin-treated patients. In the former group there was little relationship with age except for a tendency for those in the youngest and oldest groups to be hospital attenders. In the non-insulin-taking patients there was a clear relationship with age, the oldest group having few members who attended hospital regularly.

Regular effective care for diabetics not attending hospital will not take place without special arrangements for follow-up visits. Some general practices and some Health Districts have made such arrangements but they are few and far between. Of the thirty-three patients found by Doney (1976) to be attending hospital, four were also regularly seen at the practice surgery. Of the remainder, although twenty-six were reviewed by the practice, sixty-three ( $52 \%$ of the total) were not seen on a regular basis by either the hospital or their general practitioner.

There are now a small number of published studies which consider the question of the effectiveness of general-practice care compared with hospital care. Yudkin et al. (1980) found no difference between the level of diabetic control (as assessed by glycosylated haemoglobin $A_{1}$ ) in diabetics attending hospital and those not attending hospital. Control in both groups was equally poor with a mean glycosylated haemoglobin $A_{1}$ of $13.01 \%$ (upper limit of normal for their laboratory $10.5 \%$ ) in the hospital group and $13.57 \%$ in the non-hospital attenders. Other studies, such as the Cardiff randomized-discharge study (Hayes \& Harries, 1983) have found that diabetics discharged from the hospital clinic have a higher mortality and morbidity than those retained within it. 
Table I. Percentage of diabetics attending hospitals in three general-practice populations in Cambridgeshire (Williams, 1982)

\begin{tabular}{|c|c|c|c|c|c|c|}
\hline \multirow[b]{3}{*}{$\begin{array}{c}\text { Age of } \\
\text { patient (years) }\end{array}$} & \multicolumn{6}{|c|}{ Attendance at hospital } \\
\hline & \multicolumn{3}{|c|}{ Insulin-treated } & \multicolumn{3}{|c|}{ Non-insulin-treated } \\
\hline & $\begin{array}{l}\text { No. } \\
\text { attending }\end{array}$ & Total & $\begin{array}{l}\% \text { of } \\
\text { Total }\end{array}$ & $\begin{array}{c}\text { No. } \\
\text { attending }\end{array}$ & Total & $\begin{array}{l}\% \text { of } \\
\text { Total }\end{array}$ \\
\hline Under 25 & I I & I6 & 69 & 0 & o & $\circ$ \\
\hline $25-44$ & 13 & 25 & $5^{2}$ & 3 & 7 & 43 \\
\hline $45^{-64}$ & I 2 & 24 & $5^{\circ}$ & I 2 & 60 & 20 \\
\hline 65 and over & IO & I 7 & $5^{8}$ & I 5 & 108 & I4 \\
\hline All ages & $4^{6}$ & 82 & $5^{6}$ & 30 & 175 & I 7 \\
\hline
\end{tabular}

Where special schemes have been organized for the continuing management of diabetes in the community, it has been found that general practitioners express concern about two areas in particular: the diagnosis and management of diabetic retinopathy and nutrition education. In Cambridge, for example, before such a scheme was commenced in $198 \mathrm{I}$, it was known that some general practitioners in the locality, perhaps out of desperation, were giving newly-diagnosed diabetics preprinted diet cards advocating a totally inappropriate carbohydrate-restricted diet. Professional dietetic support for general practitioners who wish to improve the management of their own diabetics is seen as an essential part of any scheme which aims to encourage continuing care of the diabetic outside hospital.

At present there are insufficient community dietitians to meet the demand placed on them. Of the 202 Health Districts in England and Wales only thirty-three (16\%) are known to have a community dietitian, although it is difficult to obtain exact figures. In many districts, other dietitians spend part of their time working outside hospital.

Although in most places community dietitians spend most of their time in educating professional and non-professional groups, in some places, including Cambridge and Huntingdon, part-time community dietitians are able to see individual patients in general-practice surgeries. When dietetic services are linked in this way with a community-care scheme for diabetes then the likelihood of effective nutritional education is increased. The system seems to function most effectively when the community dietitian's session coincides with a generalpractice diabetic-clinic session and patients can easily be referred from doctor to dietitian.

At present, fourteen of the sixteen practices involved with the Cambridge community-care scheme are visited by a dietitian. The usual arrangement is for monthly visits to each practice with, for new and 'problem' patients, an initial consultation for $0.5^{-0} .75 \mathrm{~h}$ with the dietitian with one follow-up session I month later.

Although current shortages make an increase in staffing levels unlikely, additional community dietetic sessions are required if the scheme is to expand. 
Attachment of individual community dietitians to a defined area or a defined number of practices would probably make for greater efficiency and more joint sessions with general practitioners and, perhaps, more home visits to selected patients might make nutritional advice more effective. The possibility of 'self-help' groups, particularly for overweight diabetics, with periodic support from professionals has not yet been explored and it may be that, for certain individuals, this approach could work well.

The value of dietetic advice for diabetics has rarely been formally assessed and we know nothing of the relative effectiveness of giving that advice outside hospital compared with giving it in the out-patient department, in the patient's home or to 'self-help' groups. Such evaluation could take place at several levels. Assessments of dietary knowledge and attitudes are interesting although behaviour (i.e. whether the patient actually follows the advice) is of more relevance. The measurements of metabolic change and health outcome in terms of morbidity and mortality are probably beyond the scope of present studies of dietetic care since changes made in the methods of follow-up of diabetics are usually complex and the time needed to detect differences in morbidity and mortality are prohibitively long. However, small studies of dietary intake setting out to detect behavioural change after sessions with the dietitian in different settings are eminently feasible. The use of a biological marker of food intake (such as faecal weight for dietary fibre intake) would circumvent the difficulties inherent in dietary assessment by questionnaire and weighed intake.

\section{REFERENCES}

Doney, B. J. (1976). Journal of the Royal College of General Practitioners 26, 734-742. Hayes, T. M. \& Harries, J. (1983). Autumn 1983 Meeting of the Medical and Scientific Section, British Diabetic Association, Norwich.

Williams, D. R. R. (1982). Planning diabetic services in the Cambridge Health District. Dissertation for the Membership of the Faculty of Community Medicine, Royal College of Physicians, London.

Yudkin, J. S., Boucher, B. J., Schopfein, K. E., Harris, B. T., Clagg, H. R., Whyte, N. J. D., Taylor, B., Mellins, D. H., Wootliff, A. B., Safir, J. G. \& Jones, E. J. (1980). Fournal of Epidemiology and Community Health 34, 277-280. 